\title{
Controllable Biosynthesis of Small Silver Nanoparticles Using Fungal Extract
}

\author{
Katrin Quester ${ }^{1,2}$, Miguel Avalos-Borja3 ${ }^{3}$ Ernestina Castro-Longoria1 \\ ${ }^{1}$ Departamento de Microbiología, Centro de Investigación Científica y de Educación Superior de Ensenada \\ (CICESE), Ensenada, Mexico \\ ${ }^{2}$ Centro de Nanociencias y Nanotecnología, Universidad Nacional Autónoma de México (UNAM), Ensenada, \\ Mexico \\ ${ }^{3}$ División de Materiales Avanzados, Instituto Potosino de Investigación Científica y Tecnológica (IPICyT), San \\ Luis Potosí, Mexico \\ Email: ecastro@cicese.mx
}

Received 11 February 2016; accepted 26 April 2016; published 29 April 2016

Copyright (C) 2016 by authors and Scientific Research Publishing Inc.

This work is licensed under the Creative Commons Attribution International License (CC BY). http://creativecommons.org/licenses/by/4.0/

(c) (i) Open Access

\begin{abstract}
The search for reliable and eco-friendly methods for the production of nanoscale materials is an important aspect of nanotechnology. Silver nanoparticles (AgNPs) are of special interest because of their antimicrobial properties, especially those of small size. In this work, AgNPs were produced under different conditions of temperature and $\mathrm{pH}$ using the extract from the fungus Neurospora crassa as reducing agent. Mainly quasi-spherical particles were obtained at all incubation conditions. However, optimum conditions to produce small sizes in the range of $2-9 \mathrm{~nm}$ were at $4^{\circ} \mathrm{C}$ and pH 3, also particles of $2-22 \mathrm{~nm}$ were obtained at $25^{\circ} \mathrm{C}$ with unmodified $\mathrm{pH}(6.5)$ and $\mathrm{pH} \mathrm{10}$. Nevertheless, only particles synthesized at $25^{\circ} \mathrm{C}$ and $\mathrm{pH} 10$ maintained the same size range after storage of 10 months. In summary, optimal incubation conditions for the synthesis of silver nanoparticles of small size range are reported. This improves the storage time of particles without losing its original size and without going into aggregation or agglomeration.
\end{abstract}

\section{Keywords}

Biosynthesis, Nanoparticles, Neurospora crassa

\section{Introduction}

In nanobiotechnology, the so-called green-methods employ biological systems to fabricate nanostructures, which have the benefit of improving the biocompatibility of the nanomaterial [1]. Eukaryotic organisms, such as fungi, are considered excellent candidates to be used to synthesize metallic nanostructures by a purely enzymatic 
process [2]. Furthermore, in the spent medium of various strains the presence of proteins are confirmed and assumed to be responsible for the bioreduction and for stabilizing and capping the newly formed nanostructures [1]-[4] which are important advantages of using biological methods.

However, for a biological process to successfully compete with chemical and physical nanostructure synthesis, the control over average particle size range and uniform particle morphology is required [5]. It has been shown that shape and size of nanoparticles (NPs) depend on the reaction conditions [6] [7]. Therefore, it is necessary to perform experiments varying parameters such as $\mathrm{pH}$, temperature and the proportion of salts/reducing agent to fully explore the results obtained. Some publications show promising results for the synthesis of metallic NPs using extract of fungal strains [1] [6] and some studies define $\mathrm{pH}$ value and the reaction temperature as important parameters affecting nanostructure size and synthesis rate. For instance, some studies showed increasing reaction rate with increasing temperature [1] [5] [8] and alkaline $\mathrm{pH}$ was shown to increase silver particle formation [8]. However, not many studies have performed this kind of experimental procedures; therefore, the manipulation of metallic NPs synthesis is far from being exhausted. In this work, we define the optimal reduction conditions to produce AgNPs of a small size range with very good stability over time using fungal extract.

\section{Materials and Methods}

\subsection{Fungal Extract}

For extract preparations, the wild type strain of Neurospora crassa (FGSC \# 9013) was used; extract was obtained as previously described [9]. Briefly, grown biomass was filtered and washed 3 times in sterile deionized water. The biomass was ground 1:1 in deionized water (w/v) using an agate mortar, the mixture was centrifuged for 5 minutes at $6500 \mathrm{rpm}$ and filtered through a $0.2 \mu \mathrm{m}$ microfilter. The protein content of the extract was quantified by the Bradford Assay [10] in triplicate.

\subsection{Biosynthesis of Silver NPs by N. crassa Extract}

To find an optimum concentration of fungal extract for AgNPs synthesis, the extract (at known protein content concentration) was incubated with $\mathrm{AgNO}_{3}$ aqueous solution in the ratios of 1:1, 1:2, 1:3, 2:1 and 3:1 (fungal extract: metal precursor; v/v) in the dark for 12 and 24 hours at room temperature. After finding the best experimental ratio (fungal extract: metal precursor), further experiments were carried out under different environmental conditions. Synthesis of AgNPs were carried out in the dark at three different $\mathrm{pH}$ values (3, unmodified (6.5), and 10) and at five temperatures $\left(4^{\circ} \mathrm{C}, 25^{\circ} \mathrm{C}, 37^{\circ} \mathrm{C}, 60^{\circ} \mathrm{C}\right.$ and $\left.80^{\circ} \mathrm{C}\right)$, for $3,6,9$ and 12 hours of incubation. Modification of the $\mathrm{pH}$ value was realized by adding 1 molar $(\mathrm{mol} / \mathrm{L}=\mathrm{M}) \mathrm{HCl}$ or $\mathrm{NaOH}$ aqueous solution.

\subsection{TEM Analysis}

A $10 \mu \mathrm{L}$ aliquot of each sample was placed on carbon coated copper grids (300 mesh, Ted Pella Inc.) for TEM analysis under a Hitachi H-7500, JEOL 2010 and FEI Tecnai F30 transmission electron microscopes (TEM). The interplanar distance was determined using the software GatanDigitalMicrograph ${ }^{\mathrm{TM}}$.

\subsection{Statistical Analyses}

To determine significant differences between the obtained data, a factorial analysis of variance (ANOVA) was performed by using the software Statistica 7. Significance was calculated by Tukey's HSD (Honestly Significant Difference) post hoc test. Confidence intervals were set to 0.95. Error bars represent standard deviation, while significant differences are marked by an asterisk.

\section{Results}

Protein concentration of the $N$. crassa extract was $1.7 \mathrm{mg} / \mathrm{mL}$, and was incubated with $10^{-3} \mathrm{M}$ of $\mathrm{AgNO}_{3}$ solution, in the ratios of 1:1, 1:2, 1:3, 2:1 and 3:1 (fungal extract: metal precursor) at room temperature and unmodified $\mathrm{pH}$ (6.5). Very little nanoparticle formation was observed at the ratios 1:1, 2:1 and 3:1, therefore only size and shape of resulting NPs synthesized in the ratios 1:2 and 1:3 were determined via TEM after 12 and 24 hours of incubation. In all cases mainly quasi-spherical NPs were obtained, size range of particles at 1:2 ratio was 2.1 - 
$21.4 \mathrm{~nm}$ and 1.9 - $35.2 \mathrm{~nm}$ at 12 and $24 \mathrm{~h}$, respectively. Slightly smaller particles were formed at 1:3 ratio, size range was $1.9-19.5 \mathrm{~nm}$ and $1.9-21.2 \mathrm{~nm}$ at 12 and $24 \mathrm{~h}$, respectively. Since the size range for the ratio $1: 2$ was very large, which might imply the formation of less stable nanoparticles, the ratio 1:3 (fungal extract: metal precursor) was chosen for further experiments.

AgNPs were synthesized under different conditions of $\mathrm{pH}$, temperature and incubation time in order to optimize the protocol for the formation of small NPs of uniform size. It came to quasi-spherical NPs formation under all employed conditions, a summary over obtained results is shown in Table 1.

As mentioned above, nanoparticle formation was achieved under all conditions applied, but since our interest was to establish a protocol to obtain small uniform size of NPs, only promising results (NPs synthesized at $4^{\circ} \mathrm{C}$ and $\mathrm{pH} 3,25^{\circ} \mathrm{C}$ and $\mathrm{pH} 6.5$, and at $25^{\circ} \mathrm{C}$ and $\mathrm{pH} 10$ ) were further analyzed via HRTEM and EDS. Successful biosynthesis of AgNPs was already indicated by the color change of the solution from clear yellow to darker yellow upon exposure to the $\mathrm{AgNO}_{3}$ precursor solution (insets of Figures 1(A)-(C). Synthesized NPs were mainly quasi-spherical in shape in all cases (Figures 1 (A)-(C)). Figures 1(D)-(F) show TEM images of higher resolution to confirm the quasi-spherical character of the synthesized silver NPs. At least 100 particles were measured and the corresponding histograms are shown in Figures 1(G)-(I). Significant differences according to Tukey's HSD post hoc test are marked with an asterisk in Figure 2(A). Applying a temperature of $4^{\circ} \mathrm{C}$ and $\mathrm{pH} 3$ resulted in the formation of very small AgNPs in a main size range of 1 to $6 \mathrm{~nm}$ (Figure 1(A) and Figure 1(G)) being significantly smaller than the other samples (red asterisks, Figure 2(A)); however, after more than 9 hours, AgNPs showed significantly bigger sizes (blue asterisk, Figure 2(A)). At $25^{\circ} \mathrm{C}$ and unmodified $\mathrm{pH}$ (6.5), AgNPs of mainly 1 to $13 \mathrm{~nm}$ were synthesized (Figure $1(\mathrm{~B})$ and Figure $1(\mathrm{H})$ ), also with the appearance of significantly bigger NPs after 12 hours (blue asterisk, Figure 2(A)), while at $\mathrm{pH} 10$ and $25^{\circ} \mathrm{C}$ resulted in the formation of AgNPs of mainly 1 to $10 \mathrm{~nm}$ (Figure 1(C) and Figure 1(I)). Here, significantly bigger AgNPs were formed after 6 and 9 hours compared to 3 hours (blue asterisks, Figure 2(A)) while after 12 hours, the significant difference in particle size could not be observed. Determination of lattice fringe spacing of AgNPs (Figure 2(B)) confirms the planes (111) and (200) of face-centered cubic (fcc) metal silver. EDS analysis was carried out in a group of particles (Figure 2(C)) and the elemental character of synthesized AgNPs was confirmed (Figure 2(D)

Table 1. Silver NPs obtained at different incubation time and conditions at the ratio 1:3 (fungal extract: metal precursor; v/v).

\begin{tabular}{|c|c|c|c|c|c|}
\hline Temperature $\left({ }^{\circ} \mathrm{C}\right)$ & $\mathrm{pH}$ Value & $3 \mathrm{~h}$ & $6 \mathrm{~h}$ & $9 \mathrm{~h}$ & $12 \mathrm{~h}$ \\
\hline \multirow{3}{*}{4} & 3 & $1.9-5.9 \mathrm{~nm}$ & $1.7-7.2 \mathrm{~nm}$ & $2.1-9.2 \mathrm{~nm}$ & 3.7 - 28.3 nm \\
\hline & Unmodified (6.5) & $2.0-8.2 \mathrm{~nm}$ & $3.4-10.3$ nm & $3.3-40.2 \mathrm{~nm}$ & $7.5-110.3 \mathrm{~nm}$ \\
\hline & 10 & $3.5-10.4 \mathrm{~nm}$ & $2.1-6.8 \mathrm{~nm}$ & $5.9-15.8 \mathrm{~nm}$ & $10.0-41.3 \mathrm{~nm}$ \\
\hline \multirow{3}{*}{25} & 3 & $2.1-20.1 \mathrm{~nm}$ & $2.5-24.0 \mathrm{~nm}$ & $2.5-25.0 \mathrm{~nm}$ & 2.1 - $19.9 \mathrm{~nm}$ \\
\hline & Unmodified (6.5) & $1.7-22.5 \mathrm{~nm}$ & $2.5-17.4 \mathrm{~nm}$ & $1.9-21.0 \mathrm{~nm}$ & $1.9-19.5 \mathrm{~nm}$ \\
\hline & 10 & $1.0-22.5 \mathrm{~nm}$ & $1.7-21.5 \mathrm{~nm}$ & $2.1-21.7 \mathrm{~nm}$ & $1.4-21.0 \mathrm{~nm}$ \\
\hline \multirow{3}{*}{37} & 3 & $7.1-43.1 \mathrm{~nm}$ & $6.5-36.5 \mathrm{~nm}$ & $3.3-34.3 \mathrm{~nm}$ & $4.3-62.8 \mathrm{~nm}$ \\
\hline & Unmodified (6.5) & $3.3-59.9 \mathrm{~nm}$ & 3.2 - 21.9 nm & $2.3-32.0 \mathrm{~nm}$ & $2.9-26.3 \mathrm{~nm}$ \\
\hline & 10 & $7.5-96.5 \mathrm{~nm}$ & $4.4-148.0 \mathrm{~nm}$ & $2.5-44.3 \mathrm{~nm}$ & $2.9-44.9 \mathrm{~nm}$ \\
\hline \multirow{3}{*}{60} & 3 & $11.6-330.8 \mathrm{~nm}$ & $1.8-308.7 \mathrm{~nm}$ & $2.1-12.3 \mathrm{~nm}$ & $1.4-88.7 \mathrm{~nm}$ \\
\hline & Unmodified (6.5) & $3.6-44.7 \mathrm{~nm}$ & $4.1-46.1 \mathrm{~nm}$ & $2.7-36.2 \mathrm{~nm}$ & $4.3-124.9 \mathrm{~nm}$ \\
\hline & 10 & $4.2-47.9 \mathrm{~nm}$ & $1.4-93.6 \mathrm{~nm}$ & $1.4-73.8 \mathrm{~nm}$ & $1.8-8.1 \mathrm{~nm}$ \\
\hline \multirow{3}{*}{80} & 3 & 11.6 - $330.8 \mathrm{~nm}$ & $1.8-308.7 \mathrm{~nm}$ & $2.1-12.3 \mathrm{~nm}$ & $1.4-88.7 \mathrm{~nm}$ \\
\hline & Unmodified (6.5) & $2.4-20.5 \mathrm{~nm}$ & $4.3-101.0 \mathrm{~nm}$ & $2.7-23.9 \mathrm{~nm}$ & $2.7-20.5 \mathrm{~nm}$ \\
\hline & 10 & $1.9-15.4 \mathrm{~nm}$ & $2.4-35.4 \mathrm{~nm}$ & $2.4-12.4 \mathrm{~nm}$ & $17.2-409.4 \mathrm{~nm}$ \\
\hline
\end{tabular}



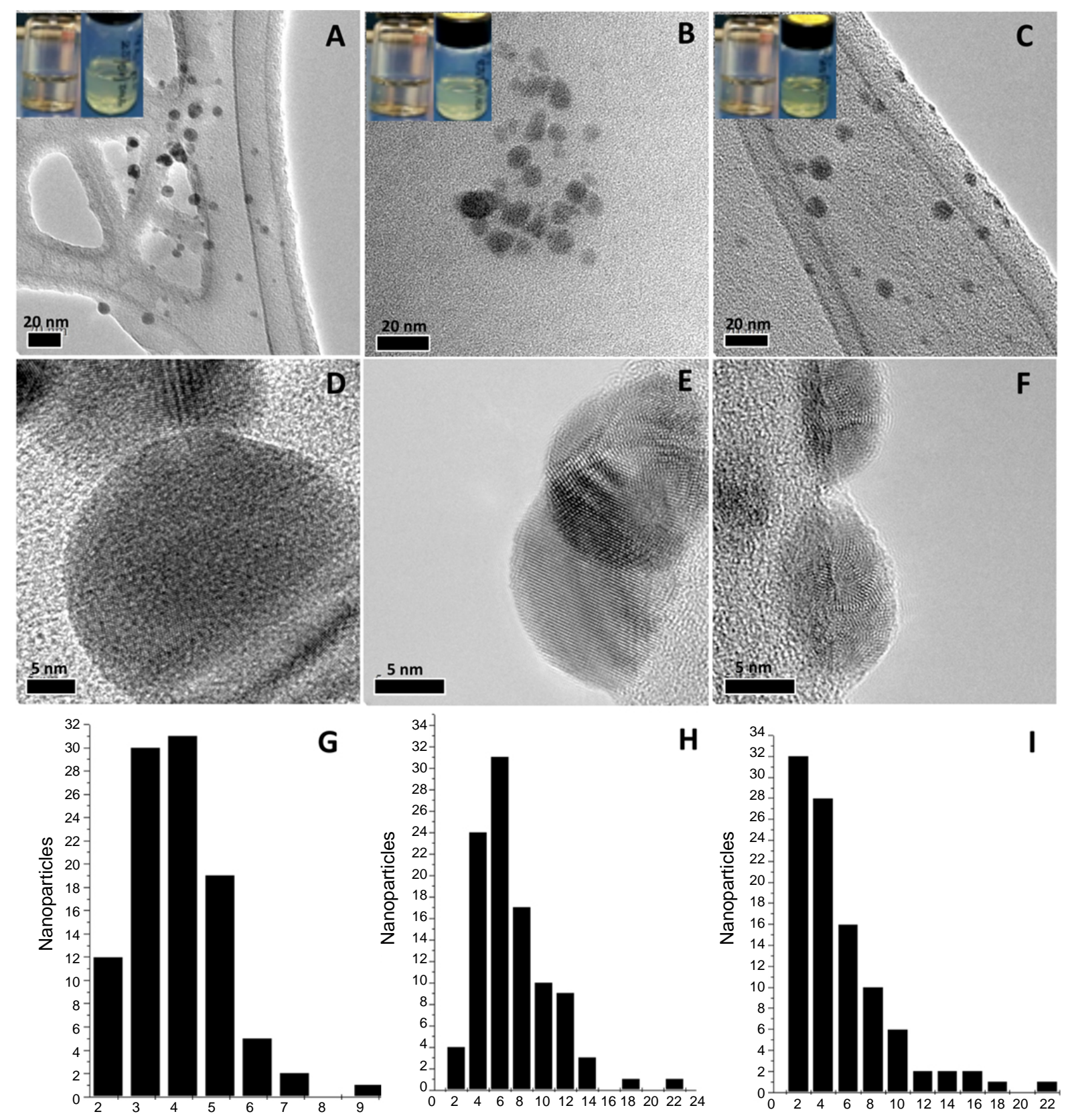

Size $(\mathrm{nm})$
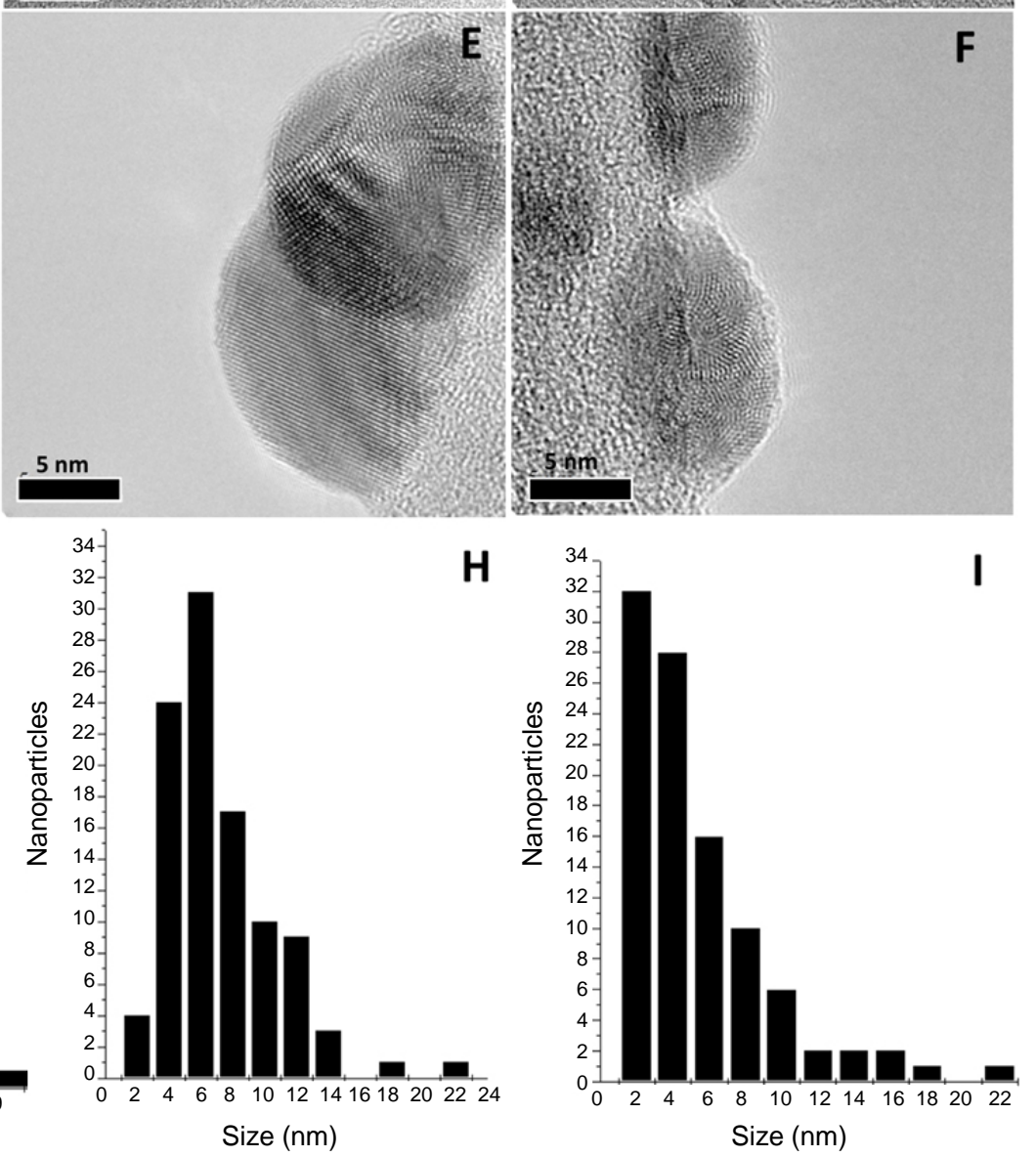

Figure 1. TEM images of silver nanoparticles synthesized by $N$. crassa extract at $4^{\circ} \mathrm{C}$ and $25^{\circ} \mathrm{C}$ and different $\mathrm{pH}$ values. $4{ }^{\circ} \mathrm{C}$ and $\mathrm{pH} 3(\mathrm{~A}$ and $\mathrm{D}), 25^{\circ} \mathrm{C}$ and $\mathrm{pH} 5.5(\mathrm{~B}$ and $\mathrm{E})$, and $25^{\circ} \mathrm{C} \mathrm{pH} 10(\mathrm{C}$ and $\mathrm{F})$. Insets: color change of fungal extract-metal precursor solution from before (clear yellow; left image) and after (darker yellow; right image) incubation. (G-I) Corresponding size distribution histograms of produced nanoparticles.

The copper signal in the spectrum corresponds to the Cu-grid used to put the sample.

The size of AgNPs was analyzed over time; HAADF-TEM images show that NPs synthesized at $4{ }^{\circ} \mathrm{C}$ and $\mathrm{pH}$ 3 incremented in size over time (Figure 3(A) and Figure 3(D)), revealing significantly bigger sizes after 10 months storage (Figure 3(G)). A similar effect was observed for AgNPs synthesized at $25^{\circ} \mathrm{C}$ and $\mathrm{pH} 6.5$ (Figure 3(B) and Figure 3(E)), although the difference is not as big as in the sample synthesized at $4^{\circ} \mathrm{C}$ and $\mathrm{pH}$ 3 (Figure 3(G)). However, AgNPs synthesized at $25^{\circ} \mathrm{C}$ and $\mathrm{pH} 10$ (Figure 3(C) and Figure 3(F)) kept their small size range without aggregation or agglomeration (Figure 3(G)). 


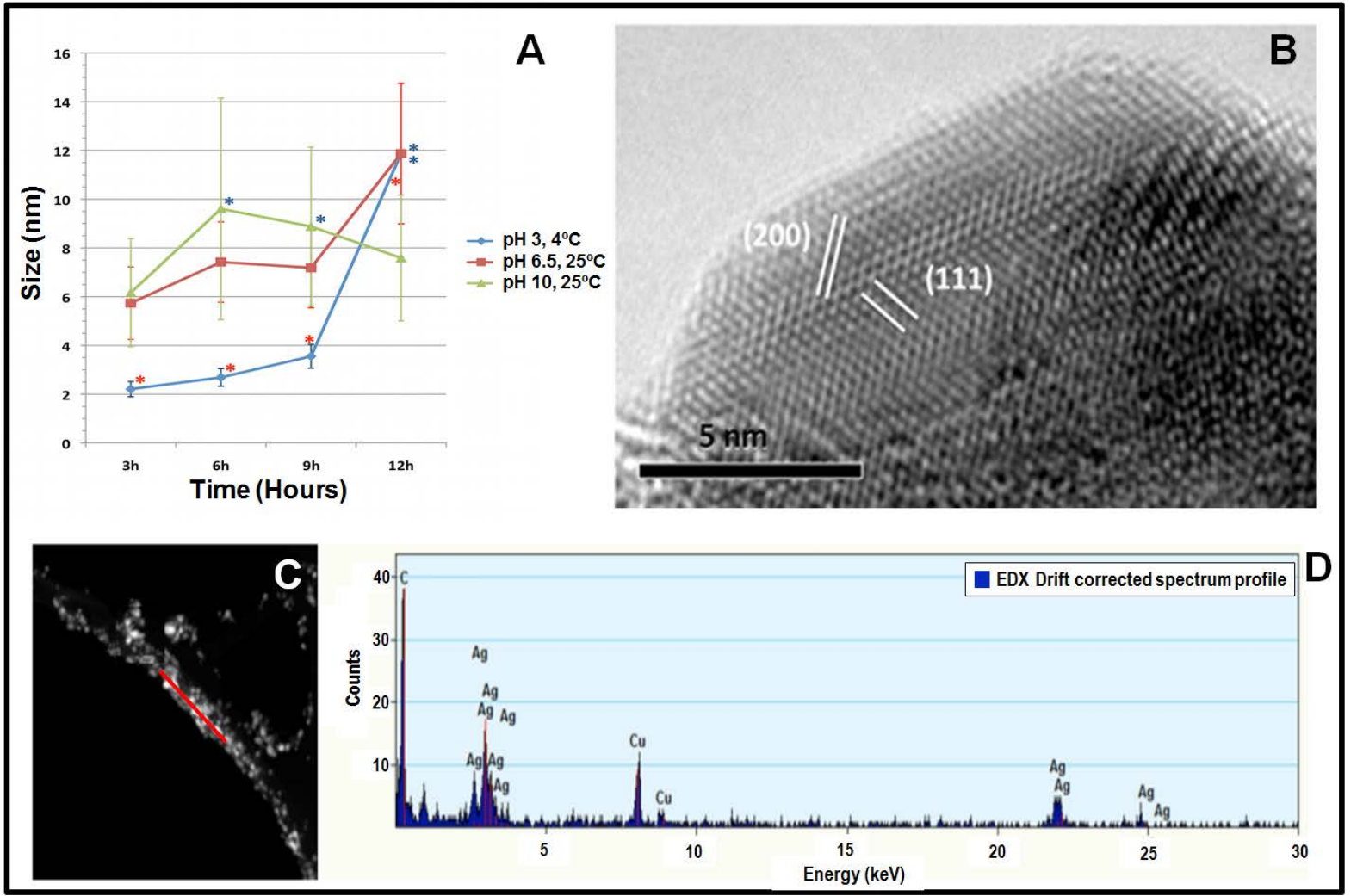

Figure 2. Analysis of size and elemental character of produced AgNPs. (A) Analysis of variance (ANOVA) of average sizes of AgNPs at different incubation times with respect to different $\mathrm{pH}$ values. Significant differences are marked with an asterisk. Confidence intervals were set to 0.95; error bars represent the standard deviation. (B) HRTEM images of a quasispherical silver nanoparticle with plane information. (C) HAADF image of silver nanoparticles. (D) EDS spectrum showing the presence of silver in the sample shown in (C). Red line in (A) indicates where the analysis was carried out.

\section{Discussion}

Neurospora crassa extract was used to biosynthesize AgNPs under different environmental conditions in order to produce small particles with narrow size dispersion. The obtained results in this study indicate that the formation of different sizes can be tuned by combining a range of temperatures with varying $\mathrm{pH}$ value. It was already shown that by changing the $\mathrm{pH}$ value and/or temperature, the resulting shapes and/or sizes of metal NPs synthesized by fungi vary [1] [7] [11] [12]; however, each fungal strain produces different metabolites and results differ among the species used. For example, optimal $\mathrm{pH}$ values for nanoparticle synthesis were shown to be alkaline for the fungus Isaria fumosorosea [13], pH 6.0 for Penicillium fellutanum [14] and acidic for Fusarium acuminatum [15].

In the case of $N$. crassa extract, it was clear that using temperatures higher than $25^{\circ} \mathrm{C}$ led to the production of bigger AgNPs, contrary to the results found by Fayaz et al. [11]. Also, at lower temperatures they found the formation of silver nanoplates while in our study, under all experimental conditions mainly quasi-spherical particles were obtained.

As mentioned above, under none of the conditions applied, AgNPs of different shapes could be obtained, even though under some conditions it came to aggregation. The reason that AgNPs came to isotropic growth might be explained by taking in account the softness of silver, based on the Hard-Soft-Acid-Base (HSAB) theory by Pearson [16]. Gold and silver are regarded as soft Pearson-acids, being large, highly polarizable ions. Pearsons' theory predicts that soft Pearson-acids show higher affinity to soft Pearson-bases and hard Pearson-acids show higher affinity to hard Pearson-bases, which results in more stable bonding. In general, proteins are assumed to be responsible for the bioreduction and for stabilizing and capping the newly formed nanostructures [1] [4] [17]. We suggest that amino groups of the proteins are responsible for the bioreduction of metal ions, since they can 

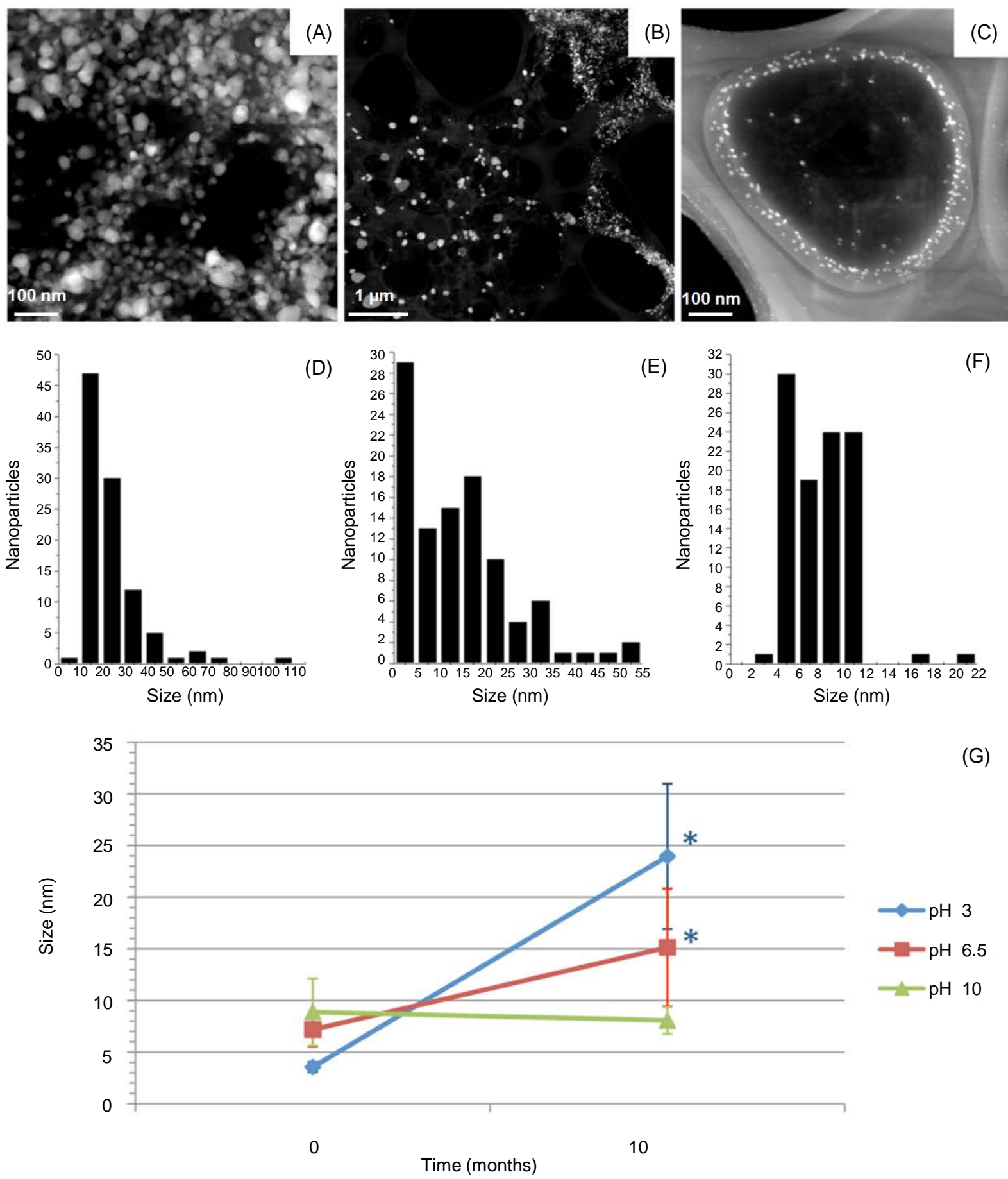

Figure 3. Analysis of AgNP size over time. HAADF-TEM micrographs and size distribution histograms of silver NPs synthesized at $4^{\circ} \mathrm{C}$ and $\mathrm{pH} 3(\mathrm{~A}$ and $\mathrm{D}), 25^{\circ} \mathrm{C}$ and $\mathrm{pH} 5.5(\mathrm{~B}$ and $\mathrm{E})$, and $25^{\circ} \mathrm{C}$ and $\mathrm{pH} 10(\mathrm{C}$ and $\mathrm{F})$ after 10 months of storage. (G) ANOVA of average sizes of silver nanoparticles after 10 months of storage compared to average sizes at time point zero (freshly synthesized). Significant differences are marked with an asterisk. Confidence intervals were set to 0.95. Error bars represent the standard deviation.

donate electrons quite easily while releasing a proton. Nitrogen is regarded as a less soft, or borderline base and Nath et al. [18] realized studies about the grade of softness of gold and silver by determining the binding affinity of these metals to nitrogen and sulfur; the latter being a softer Pearson-base. The authors showed that silver is a 
less soft Pearson-acid than gold, possessing much stronger affinity to the less soft nitrogen atom, while the softer gold bound stronger to the softer sulfur atom. Therefore, due to its higher binding affinity, the bioreduction process between amino groups and silver ions might be faster due to a quicker immobilization of the silver ions by the amino groups of the proteins, which thereby results in isotropic growth of AgNPs even at low $\mathrm{pH}$ values, based on the statement of $\mathrm{Li}$ and Kaner [19], declaring that in a faster reaction, it is more likely that the embryonic nuclei evolve to create homogenous nuclei before they can diffuse to heterogeneous nucleation sites to nucleate. As stated above, carboxyl groups are less effective stabilizers at lower $\mathrm{pH}$ values, which might be the reason of variations in AgNPs sizes between the samples.

The exact mechanisms are still not fully understood and much more investigation needs to be done to gain a better understanding and the ability to further manipulate size and shape of biosynthesized metal NPs. Meanwhile, the results in this study indicate that under certain temperatures and $\mathrm{pH}$ values small size range of particles with very good stability can be produced.

\section{Conclusion}

Silver nanoparticles of small size have been successfully produced using a simple green methodology. Furthermore, we have demonstrated that biosynthesis of nanoparticles using fungal extract can be optimized and that under specific conditions of $\mathrm{pH}$ and temperature, the size of particles can be maintained for at least 10 months without aggregation or agglomeration.

\section{Acknowledgements}

We thank CONACyT for a scholarship for KQ. We also thank LINAN for providing access to electron microscopy facilities, Dr. Nicolás Cayetano Castro and Dr. Héctor Gabriel Silva Pereyra (LINAN-IPICyT) for helping in TEM characterization. Part of this work was funded by a SEP-CONACyT grant (CB2011/169154).

\section{References}

[1] Xie, J., Lee, J.Y., Wang, D.I. and Ting, Y.P. (2007) High-Yield Synthesis of Complex Gold Nanostructures in a Fungal System. The Journal of Physical Chemistry C, 111, 16858-16865. http://dx.doi.org/10.1021/jp0752668

[2] Ahmad, A., Mukherjee, P., Mandal, D., Senapati, S., Khan, M.I., Kumar, R. and Sastry, M. (2002) Enzyme Mediated Extracellular Synthesis of CdS Nanoparticles by the Fungus, Fusarium oxysporum. Journal of the American Chemical Society, 124, 12108-12109. http://dx.doi.org/10.1021/ja027296o

[3] Mukherjee, P., Roy, M., Mandal, B.P., Dey, G.K., Mukherjee, P.K., Ghatak, J., Tyagi, A.K. and Kale, S.P. (2008) Green Synthesis of Highly Stabilized Nanocrystalline Silver Particles by a Non-Pathogenic and Agriculturally Important Fungus T. asperellum. Nanotechnology, 19, 075103. http://dx.doi.org/10.1088/0957-4484/19/7/075103

[4] Vigneshwaran, N., Kathe, A.A., Varadarajan, P.V., Nachane, R.P. and Balasubramanya, R.H. (2007) Silver-Protein (Core-Shell) Nanoparticle Production Using Spent Mushroom Substrate. Langmuir, 23, 7113-7117. http://dx.doi.org/10.1021/la063627p

[5] Gericke, M. and Pinches, A. (2006) Biological Synthesis of Metal Nanoparticles. Hydrometallurgy, 83, 132-140. http://dx.doi.org/10.1016/j.hydromet.2006.03.019

[6] Das, S.K., Das, A.R. and Guha, A.K. (2010) Microbial Synthesis of Multishaped Gold Nanostructures. Small, 6, 10121021. http://dx.doi.org/10.1002/smll.200902011

[7] Sanghi, R. and Verma, P. (2010) pH Dependant Fungal Proteins in the "Green” Synthesis of Gold Nanoparticles. Advanced Materials Letters, 1, 193-199. http://dx.doi.org/10.5185/amlett.2010.5124

[8] Qian, Y., Yu, H., He, D., Yang, H., Wang, W., Wan, X. and Wang, L. (2013) Biosynthesis of Silver Nanoparticles by the Endophytic Fungus Epicoccum nigrum and Their Activity against Pathogenic Fungi. Bioprocess and Biosystems Engineering, 36, 1613-1619. http://dx.doi.org/10.1007/s00449-013-0937-z

[9] Quester, K., Avalos-Borja, M., Vilchis-Nestor, A.R., Camacho-López, M.A. and Castro-Longoria, E. (2013) SERS Properties of Different Sized and Shaped Gold Nanoparticles Biosynthesized under Different Environmental Conditions by Neurospora crassa Extract. PLoS ONE, 8, e77486. http://dx.doi.org/10.1371/journal.pone.0077486

[10] Bradford, M.M. (1976) A Rapid and Sensitive Method for the Quantitation of Microgram Quantities of Protein Utilizing the Principle of Protein-Dye Binding. Analytical Biochemistry, 72, 248-254. http://dx.doi.org/10.1016/0003-2697(76)90527-3

[11] Fayaz, A.M., Balaji, K., Kalaichelvan, P.T. and Venkatesan, R. (2009) Fungal Based Synthesis of Silver Nanopar- 
ticles-An Effect of Temperature on the Size of Particles. Colloids and Surfaces B: Biointerfaces, 74, 123-126. http://dx.doi.org/10.1016/j.colsurfb.2009.07.002

[12] Philip, D. (2009) Biosynthesis of Au, Ag and Au-Ag Nanoparticles Using Edible Mushroom Extract. Spectrochimica Acta, Part A: Molecular and Biomolecular Spectroscopy, 73, 374-381. http://dx.doi.org/10.1016/j.saa.2009.02.037

[13] Banu, A.N. and Balasubramanian, C. (2014) Optimization and Synthesis of Silver Nanoparticles Using Isaria fumosorosea against Human Vector Mosquitoes. Parasitology Research, 113, 3843-3851. http://dx.doi.org/10.1007/s00436-014-4052-0

[14] Kathiresan, K., Manivannan, S., Nabeel, M.A. and Dhivya, B. (2009) Studies on Silver Nanoparticles Synthesized by a Marine Fungus, Penicillium fellutanum Isolated from Coastal Mangrove Sediment. Colloids and Surfaces B: Biointerfaces, 71, 133-137. http://dx.doi.org/10.1016/j.colsurfb.2009.01.016

[15] Tidke, P.R., Gupta, I., Gade, A.K. and Rai, M. (2014) Fungus-Mediated Synthesis of Gold Nanoparticles and Standardization of Parameters for its Biosynthesis. IEEE Transactions on NanoBioscience, 13, 397-402.

[16] Pearson, R.G. (1993) The Principle of Maximum Hardness. Accounts of Chemical Research, 26, 250-255. http://dx.doi.org/10.1021/ar00029a004

[17] Mukherjee, P., Senapati, S., Mandal, D., Ahmad, A., Khan, M.I., Kumar, R. and Sastry, M. (2002) Extracellular Synthesis of Gold Nanoparticles by the Fungus Fusarium oxysporum. ChemBioChem, 3, 461-463. http://dx.doi.org/10.1002/1439-7633(20020503)3:5<461::AID-CBIC461>3.0.CO;2-X

[18] Nath, S., Ghosh, S.K., Kundu, S., Praharaj, S., Panigrahi, S. and Pal, T. (2006) Is Gold Really Softer than Silver? HSAB principle revisited. Journal of Nanoparticle Research, 8, 111-116. http://dx.doi.org/10.1007/s11051-005-8025-1

[19] Li, D. and Kaner, R.B. (2006) Shape and Aggregation Control of Nanoparticles: Not Shaken, Not Stirred. Journal of the American Chemical Society, 128, 968-975. http://dx.doi.org/10.1021/ja056609n 